\title{
WILEY-VCH
}

DOI: $10.1002 /(($ please add manuscript number $))$

Article type: Communication

\section{Bandgap-Tunable Caesium Lead Halide Perovskites with High Thermal Stability for Efficient Solar Cells}

Rebecca J. Sutton, Giles E. Eperon, Laura Miranda, Elizabeth S. Parrott, Brett A. Kamino, Jay B. Patel, Maximilian T. Hörantner, Michael B. Johnston, Amir Abbas Haghighirad, David T. Moore, and Henry J. Snaith*

R. J. Sutton, Dr. G. E. Eperon, E. S. Parrott, J. B. Patel, M. T. Hörantner, Prof. M. B. Johnston, Dr. A. A. Haghighirad, Dr. D. T. Moore, Prof. H. J. Snaith

Department of Physics, Clarendon Laboratory, University of Oxford, Oxford OX1 3PU, United Kingdom

E-mail: henry.snaith@physics.ox.ac.uk

Dr. L. Miranda, Dr. B. A. Kamino

Oxford PV Ltd. Begbroke Science Park, Woodstock Road, Oxford, OX5 1PF, United Kingdom

Keywords: perovskite, solar cells, inorganic perovskites, photovoltaics, thermal stability, caesium

\section{Abstract}

Hybrid organic-inorganic metal halide perovskites have been the subject of extensive research over the last few years due to their increasingly impressive solar cell performance. However, these materials are known to suffer from thermal degradation at relatively low temperatures in comparison to conventional inorganic semiconductors, thought to be due to the relatively volatile organic component. Here we present a detailed investigation into inorganic caesium lead tri-halide perovskite materials. We find we can form solid solutions of mixed bromideiodide halide perovskites as films, where the absorption onset ranges from $2.35 \mathrm{eV}$ for $\mathrm{CsPbBr}_{3}$ to $1.73 \mathrm{eV}$ for $\mathrm{CsPbI}_{3}$. We show bandgap tunability with a single step solution processing route for the lower bandgap range, and significantly increased stability in air with increased bromide content. For an optimal balance of band gap and stability, we demonstrate efficient solar cells using $\mathrm{CsPbI}_{2} \mathrm{Br}$, with $9.8 \%$ current-voltage scan efficiency and $5.6 \%$ stabilized efficiency. We demonstrate that this material is significantly more thermally stable than methylammonium lead tri-halide perovskites, more stable under operating temperatures 


\section{WILEY-VCH}

in air, and hence may prove to be ideally suited for use in tandem solar cells especially for applications where high operating temperatures are required.

\section{Introduction}

Hybrid organic-inorganic halide perovskite materials have been well-studied in the past few years, and solar cells using these materials have seen a rapid rise in efficiency from $3.8 \%$ to over $20 \%$ in less than 5 years. ${ }^{[1-4]}$ These materials typically comprise organic cations, such as methylammonium (MA) and/or formamidinium (FA), in a lead halide framework. ${ }^{[5]}$ Although these hybrid perovskite solar cells exhibit high efficiencies, the thinfilm perovskite absorber layers are subject to compositional degradation due to both heat and humidity, ${ }^{[6]}$ therefore, addressing the long term stability is a primary concern for the community. ${ }^{[7]}$ Compositional stability under thermal stressing is particularly important for solar cell operation; for certification solar modules must be able to operate successfully between temperatures of $-40{ }^{\circ} \mathrm{C}$ and $+85^{\circ} \mathrm{C}$, and in some geographic locations of high solar irradiance these upper operating temperatures can be regularly reached. ${ }^{[8]}$

Although bulk powders and single crystals of $\mathrm{MAPbI}_{3}$ do not undergo thermal decomposition until temperatures in excess of $200{ }^{\circ} \mathrm{C},{ }^{[9,10]}$ achieving such thermal stability in thin films of the hybrid perovskites is challenging due to the high surface to volume ratio as well as the inherent instability of the organic cation. Specifically, thin films of methylammonium lead iodide thermally degrade to lead iodide at temperatures above $85^{\circ} \mathrm{C} .^{[6]}$ Formamidinium perovskites are much more thermally stable than methylammonium perovskites, ${ }^{[5]}$ and it has recently been shown that thin films of mixtures of organic formamidinium and inorganic caesium (Cs) cations can be both structurally and thermally stable above $100{ }^{\circ} \mathrm{C}^{[11,12]}$ However, the ultimate avenue for improving the thermal compositional stability is to replace the organic component entirely with an inorganic cation such as caesium. The fully inorganic caesium lead halides have been known since their first synthesis in $1893 .{ }^{[13]}$ Since the initial 


\section{WILEY-VCH}

report, there have been many studies of the properties of caesium lead halides, ${ }^{[14-21]}$ and these materials are now garnering interest from both the photovoltaic and light emission communities with a few recent reports of them being used in solar cells and as emissive nanocrystals. $^{[22-27]}$

These previous reports give us much insight into the compositional and structural phase stability of these inorganic perovskites. We consider here caesium lead bromide $\left(\mathrm{CsPbBr}_{3}\right)$ and caesium lead iodide $\left(\mathrm{CsPbI}_{3}\right)$ : both of these compounds are compositionally stable up to their melting points which are in excess of $460{ }^{\circ} \mathrm{C} .{ }^{[16]} \mathrm{CsPbr}_{3}$ crystallizes in an orthorhombic phase at room temperature, and transitions to a tetragonal perovskite phase at $88{ }^{\circ} \mathrm{C}$ and to the “orange" cubic perovskite phase at $130{ }^{\circ} \mathrm{C} .^{[21,22]} \mathrm{In}$ contrast, $\mathrm{CsPbI}_{3}$ is stable in an orthorhombic non-perovskite structure (yellow phase) at room temperature, and changes to the cubic perovskite (black phase) when heated above $\sim 300{ }^{\circ} \mathrm{C} .{ }^{[14,16]}$ Unfortunately, $\mathrm{CsPbI}_{3}$ is unstable in the black perovskite phase in ambient atmosphere and rapidly converts to the nonperovskite yellow phase. ${ }^{[14,23]}$ We note that for nanocrystals on the order of $5 \mathrm{~nm}$ in size, these phase transitions appear to be altered such that nanocrystals of $\mathrm{CsPbI}_{3}$ are more stable in the cubic phase at room temperature than bulk $\mathrm{CsPbI}_{3}$, although both revert to the nonperovskite phase over time. ${ }^{[25]}$ We expect the phase transitions in the polycrystalline films to be similar to those in the bulk. Hence, for these materials, it is apparent that the structural stability is the important parameter to resolve, rather than the compositional stability, under terrestrial solar cell operating temperatures.

In the mixed-halide region between $\mathrm{CsPbBr}_{3}$ and $\mathrm{CsPbI}_{3}$, solid solutions form in the bulk material. $^{[16]}$ However, for thin films, solution processing is difficult for the bromide-rich compositions, due to solubility limitations of the bromide ion. This problem was recently overcome by using a two-step method to make films of neat $\mathrm{CsPbr}_{3}$, and subsequent solar cells using $\mathrm{CsPbrr}_{3}$ as the light absorbing material. ${ }^{[22]}$ 


\section{WILEY-VCH}

Here, we show that this two-step method can be used to form the full series of caesium lead halide perovskite thin films from $\mathrm{CsPbBr}$ to $\mathrm{CsPbI}_{3}$. However, we find that uniform film deposition is challenging. In contrast, we demonstrate that with a one-step solution processing route we can create uniform thin films of caesium perovskites with high iodide content. Based on these results we select an appropriate mixed-halide composition with increased structural stability in ambient atmosphere. With this $1.92 \mathrm{eV}$ band gap material we obtain solar cells which operate in air at room temperature with close to $10 \%$ power conversion efficiency.

\section{Results}

Initially, we demonstrate that an adaptation of the two-step method reported by Kulbak et $a l .^{[22]}$ can be used to form the full series of caesium lead halide perovskites. The first step is to spin-coat lead bromide in dimethylformamide (DMF) onto a mesoporous $\mathrm{TiO}_{2}$ scaffold, and dry at $70{ }^{\circ} \mathrm{C}$. When dry, these lead bromide films are dipped for ten minutes in a heated solution of the caesium halide salt(s) in methanol. We subsequently anneal these films at high temperature $\left(250-350{ }^{\circ} \mathrm{C}\right)$, to form the cubic perovskite. Here, we mix various ratios of CsI and $\mathrm{CsBr}$ in the dipping solution, and successfully obtain the perovskite films with varying halide composition. We provide further details, such as photographs and absorbance spectra, in the Supporting Information (Figure S1). We find that the absorbance onset of these films is tunable from $530 \mathrm{~nm}$ to $700 \mathrm{~nm}$, consistent with solid solutions of iodide and bromide mixtures forming. Intriguingly, we observe that the composition of the perovskite film is skewed towards the dominant halide in solution: all films were dipped for an equal time (10 minutes), and prior literature suggests that the possibility of ion exchange may mean that the composition is additionally dependent on dipping time. ${ }^{[28-30]}$ Although the absorbance and color of such films appears promising, we observe in scanning electron micrographs of the 


\section{WILEY-VCH}

cross-section of the films that the morphology is not optimal for solar cells, with prevalence of protruding wire-shaped crystals.

In order to obtain much smoother films, we instead pursue a one-step solution processing method. For $\mathrm{CsPbI}_{3}$ we have previously shown that the precursors are readily soluble in DMF, and subsequent spin-coating yields smooth and uniform thin films, especially with the addition of hydriodic acid (HI) which allows formation of the black phase at $100{ }^{\circ} \mathrm{C} .{ }^{[23]} \mathrm{We}$ found that by this one-step solution process we could form useable films with up to one third of the total halide content as bromide (denoted here as $\mathrm{CsPbI}_{2} \mathrm{Br}$ ); above this bromide content the solubility of the bromide ion is limiting in DMF. These films were annealed at high temperature since our attempts to use hydriodic and/or hydrobromic acid to lower the crystallization temperature were unsuccessful for the mixed halide compositions. In Figure 1 we show absorption and luminescence (PL) spectra for films of iodide/bromide mixtures from $\mathrm{CsPbI}_{3}$ to $\mathrm{CsPbI}_{2} \mathrm{Br}$. We observe a shift in the absorption onset (Figure 1a) and photoluminescence peak (Figure 1b) to shorter wavelengths with increasing bromide concentration. In Figure 1c, we plot these energies as a function of iodide content, ' $x$ ' in $\operatorname{CsPb}\left(\mathrm{I}_{\mathrm{x}} \mathrm{Br}_{1-\mathrm{x}}\right)_{3}$; the linear trend we observe for the absorbance follows Vegard's law, indicating that solid solutions of the iodide-bromide mixtures are formed throughout this series (see Figure $\mathbf{S 3}$ for EDX of the composition $\mathrm{CsPbI}_{2} \mathrm{Br}$ ). This hypothesis is further supported by observations by Sharma et al. that the cubic lattice parameter varies linearly and the solid to liquid phase transition is continuous from caesium lead bromide to caesium lead iodide. ${ }^{[16]}$ We note that for only a small amount of bromide, the photoluminescence peak is nearer the neat iodide than expected, suggesting there may be microscopic regions of inhomogeneity for this composition. 
WILEY-VCH
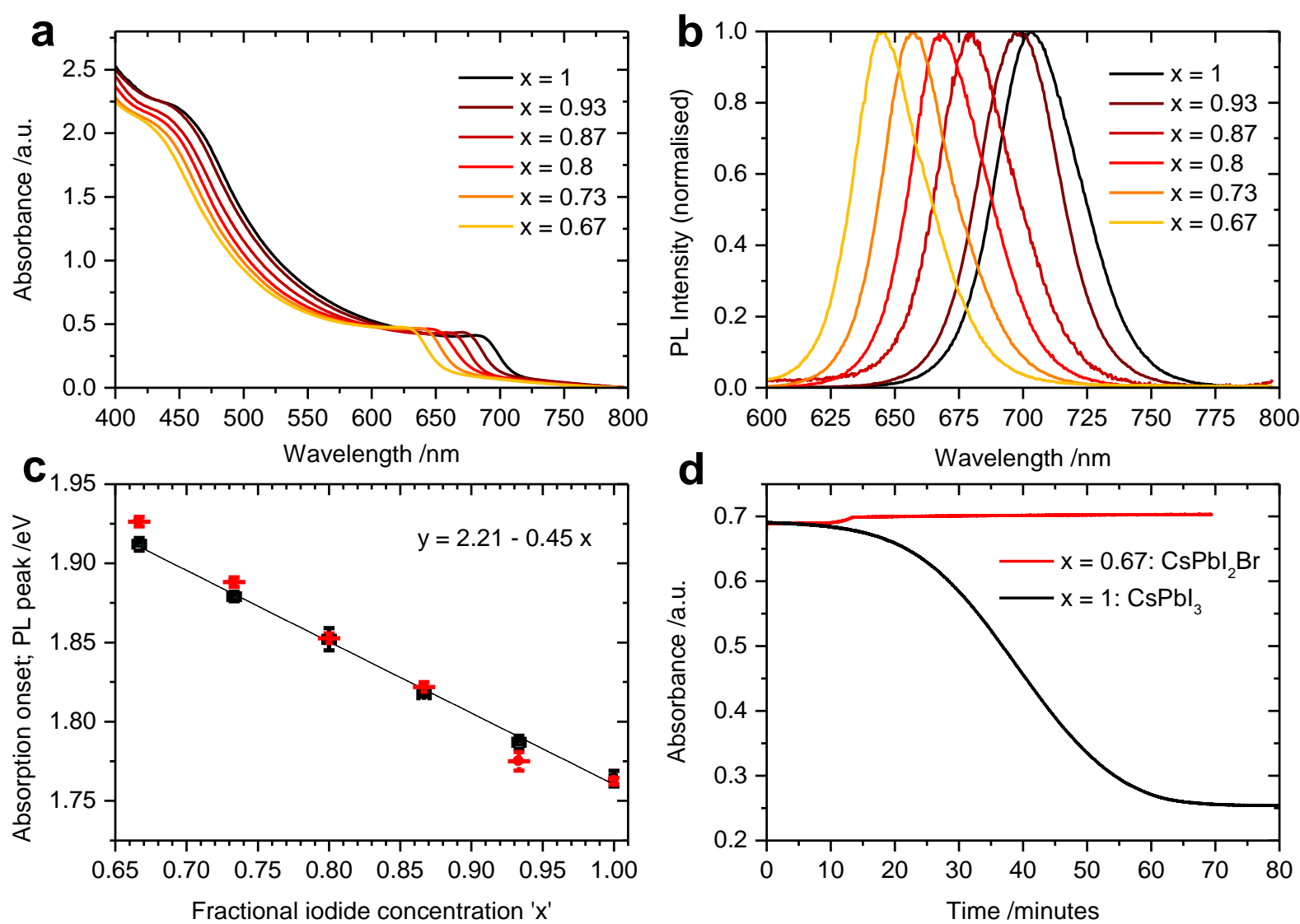

Figure 1. a) Absorbance spectra and b) photoluminescence (PL) spectra for mixed halide $\left.\mathrm{CsPb}_{(\mathrm{x}} \mathrm{Ir}_{1-\mathrm{x}}\right)_{3}$ films with varying iodide concentration ' $x$ '. These films were annealed at $330-350{ }^{\circ} \mathrm{C}$, and measured in nitrogen or under vacuum respectively. PL spectra were excited using a tunable pulsed laser at $410 \mathrm{~nm}$ with a spot size of $\sim 0.2 \mathrm{~mm}^{2}$. c) Absorbance onsets (black squares), determined by Tauc plots of absorbance spectra taken with an integrating sphere, and PL peak positions (red circles); solid line is the linear fit to the absorbance. Error bars indicate the range of values obtained. d) Absorbance over time of thin films of $\mathrm{CsPbI}_{3}$ and $\mathrm{CsPbI}_{2} \mathrm{Br}$, measured at 675 and $625 \mathrm{~nm}$ respectively, when exposed to a slow flow of air at $50 \% \mathrm{RH}$. The slight increase in the absorbance of the $\mathrm{CsPbI}_{2} \mathrm{Br}$ film is not yet fully understood.

We previously observed that despite being able to form the black phase of $\mathrm{CsPb}_{3}$ at low temperatures in an inert environment, once exposed to air, these films rapidly underwent a phase transition to the thermodynamically stable yellow phase. We are yet to fully understand this phase transition, but our assumption is that partial hydration of the crystal reduces the energy barrier required to surmount the phase transition. In Figure 1d we show the relative instability of $\mathrm{CsPbI}_{3}$ compared with $\mathrm{CsPbI}_{2} \mathrm{Br}$. We find that for a thin film enclosed in a nitrogen chamber with a low flow of air $(50 \% \mathrm{RH}), \mathrm{CsPbI}_{3}$ reverts to the low temperature 


\section{WILEY-VCH}

yellow phase in about an hour, while $\mathrm{CsPbI}_{2} \mathrm{Br}$ is stable under the same conditions. It is known that the phase transition temperature for the orthorhombic to cubic perovskite transition reduces with increasing bromide content. ${ }^{[16]}$ We expect the lower phase transition temperature to be the predominant reason for the enhanced stability of the $\mathrm{CsPbI}_{2} \mathrm{Br}$ under ambient conditions. We therefore take encouragement that the $\mathrm{CsPbI}_{2} \mathrm{Br}$ is a promising material which appears to combine ambient stability and suitable bandgap and thus warrants further investigation for solar cell applications. In particular, its bandgap of $1.92 \mathrm{eV}$ makes it promising as an option for inclusion in tandem devices with c-Si and copper indium gallium (di)selenide solar cells. ${ }^{[31]}$

To verify that the addition of bromide reduces the transition temperature for thin films, and to prove the inherent thermal stability of these material at elevated temperatures, we measured in-situ X-ray diffraction (XRD) spectra while heating films of $\mathrm{CsPbI}_{3}$ and $\mathrm{CsPbI}_{2} \mathrm{Br}$ at temperatures up to $400{ }^{\circ} \mathrm{C}$ (shown in Figure S4 in the SI). We observe the perovskite crystal begin to form around $350{ }^{\circ} \mathrm{C}$ for $\mathrm{CsPbI}_{3}$ and around $230{ }^{\circ} \mathrm{C}$ for $\mathrm{CsPb}_{2} \mathrm{Br}$, a reduction of over $100{ }^{\circ} \mathrm{C}$ in the transition temperature. ${ }^{[16,19]} \mathrm{We}$ also find that for $\mathrm{CsPbI}_{2} \mathrm{Br}$ the $\mathrm{XRD}$ peaks are slightly offset from those of the high temperature black phase of $\mathrm{CsPbI}_{3}$ due to the bromide content which is expected to contract the lattice (see Figure 2c). We note that for a thin film of $\mathrm{CsPb}_{2} \mathrm{Br}$ we find optimal crystallinity and absorbance when annealing at $350{ }^{\circ} \mathrm{C}$. Remarkably, it is well-known that at such high temperatures thin films of the hybrid organicinorganic perovskites such as methylammonium (MA) and formamidinium (FA) lead iodide degrade very rapidly. ${ }^{[5,6]}$ Specifically, $\mathrm{MAPbI}_{3}$ thin films will start to thermally degrade at temperatures above $85^{\circ} \mathrm{C}$, and $\mathrm{FAPbI}_{3}$ thin films at temperatures above $150{ }^{\circ} \mathrm{C}$.

To further illustrate the thermal and atmospheric stability of $\mathrm{CsPbI}_{2} \mathrm{Br}$ under conditions more similar to solar cell operating conditions, we compare it to thin films of the organic methylammonium equivalent, $\mathrm{MAPbI}_{2} \mathrm{Br}$ perovskite, at $85{ }^{\circ} \mathrm{C}$ in air. In Figure 2 we show absorption and $\mathrm{XRD}$ spectra for films of $\mathrm{CsPbI}_{2} \mathrm{Br}$ and $\mathrm{MAPbI}_{2} \mathrm{Br}$ heated on a hotplate at 


\section{WILEY-VCH}

$85{ }^{\circ} \mathrm{C}$ in air in a controlled humidity environment of between 20 and $25 \% \mathrm{RH}$. For $\mathrm{CsPbI}_{2} \mathrm{Br}$, in Figure 2a we observe that after 270 minutes of heating the absorbance remains approximately constant (within the spot to spot measurement accuracy) with the initial absorbance at $627 \mathrm{~nm}$. In the XRD spectra in Figure 2c we see peaks characteristic of the $\mathrm{CsPb}_{2} \mathrm{Br}$ perovskite phase both before and after heating, and no peaks indicating other material compositions or degradation. In contrast, for $\mathrm{MAPbI}_{2} \mathrm{Br}$ in Figure $\mathbf{2 b}$ we observe a continuous decrease in the perovskite absorbance at $670 \mathrm{~nm}$ over 270 minutes of heating, such that after heating the film appears visibly yellow. The XRD spectra in Figure 2d show perovskite peaks for $\mathrm{MAPbI}_{2} \mathrm{Br}$ before heating; after heating new peaks appear, including a $\mathrm{PbI}_{2-\mathrm{x}} \mathrm{Br}_{\mathrm{x}}$ peak near $13^{\circ}$ which indicates that $\mathrm{MABr}$ and/or MAI have been removed. From this figure we conclude that $\mathrm{CsPb}_{2} \mathrm{Br}$ shows both phase and compositional stability when heated at $85{ }^{\circ} \mathrm{C}$ in $20-25 \% \mathrm{RH}$, while $\mathrm{MAPbI}_{2} \mathrm{Br}$ shows compositional instability under the same conditions. 

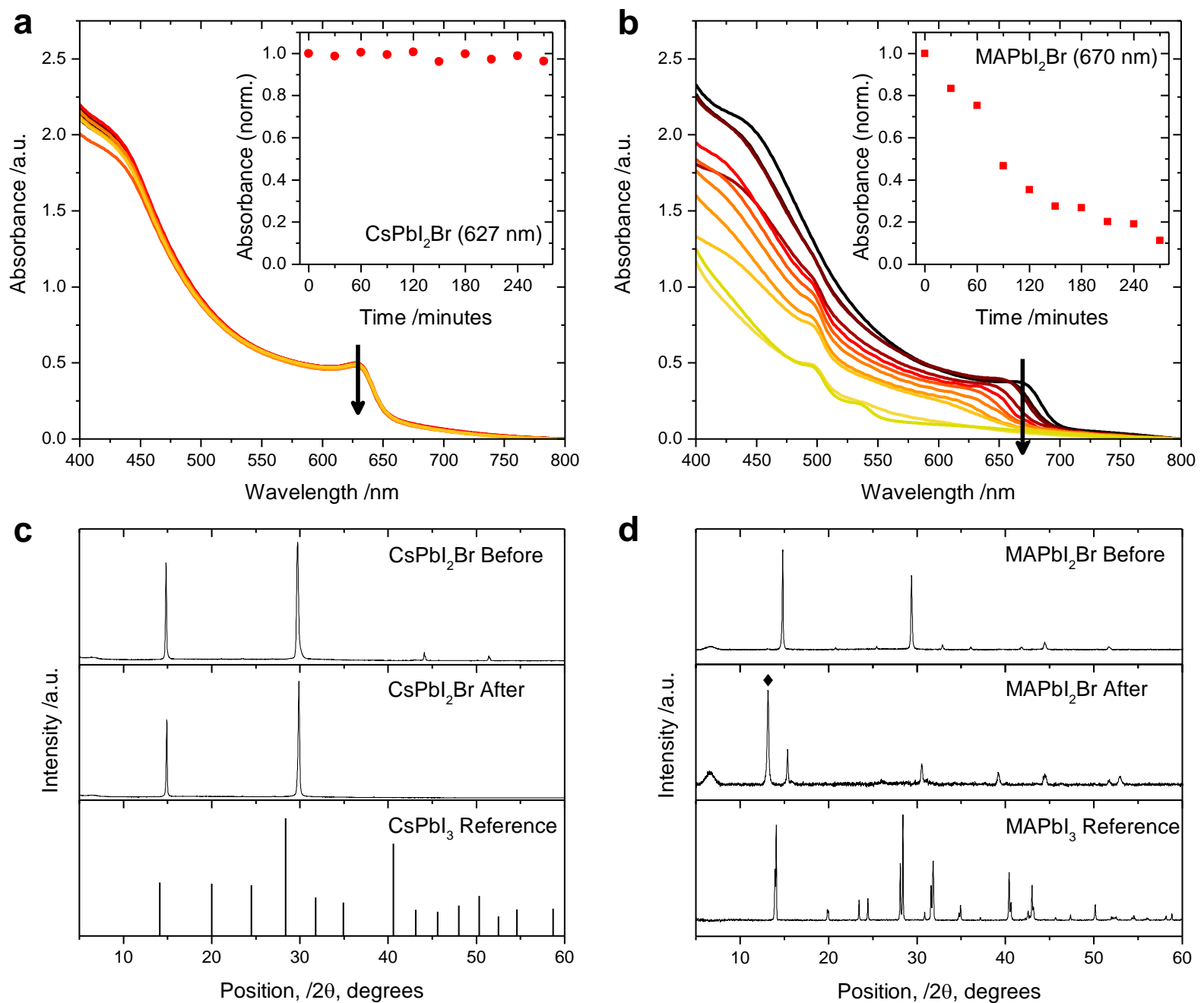

Figure 2. Absorbance spectra for films of a) $\mathrm{CsPbI}_{2} \mathrm{Br}$ and b) $\mathrm{MAPbI}_{2} \mathrm{Br}$ for different times of heating at $85{ }^{\circ} \mathrm{C}$ in 20 -

$25 \%$ RH. Arrows indicate direction of increasing time of heating. Insets: absorption intensity over time at peak of onset $(627 \mathrm{~nm}$ and $670 \mathrm{~nm}$ respectively; arrow positions in main plot). XRD spectra before and after 270 minutes of heating at $85{ }^{\circ} \mathrm{C}$ in $20-25 \% \mathrm{RH}$ for c) $\mathrm{CsPbI}_{2} \mathrm{Br}$ and d) $\mathrm{MAPbI}_{2} \mathrm{Br}$. The reference powder pattern for $\mathrm{CsPbI}_{3}\left(\mathrm{cubic}^{2}\right.$ phase) is from Trots and Myagkota; ${ }^{[19]}$ the $\mathrm{MAPbI}_{3}$ (tetragonal phase) powder pattern is from a crushed single crystal. X-ray absorbance due to the Kapton film is seen below $2 \theta=10^{\circ}$; the $\mathrm{PbI}_{2-\mathrm{x}} \mathrm{Br}_{\mathrm{x}}$ peak position is indicated by a diamond.

We have shown that for this mixed-halide composition, $\mathrm{CsPb}_{2} \mathrm{Br}$, the ambient stability is greatly increased such that it should now be possible to make solar cells with this material and test them under ambient conditions. To empirically verify that the carrier diffusion length is sufficient in this material, we prepared two different device architectures (see Figure S5): a planar architecture with only compact $\mathrm{TiO}_{2}\left(\mathrm{c}-\mathrm{TiO}_{2}\right)$ as the n-type charge collection layer, which requires a material with sufficient charge mobility and carrier lifetime for extraction of 


\section{WILEY-VCH}

charges; and a mesoporous architecture, where the inclusion of a mesoporous $\mathrm{TiO}_{2}\left(\mathrm{~m}-\mathrm{TiO}_{2}\right)$ layer allows electrons to be extracted from the perovskite much closer to the site of generation. The final device configuration is glass/FTO/c- $\mathrm{TiO}_{2} / \mathrm{m}-\mathrm{TiO}_{2}$ (optional)/perovskite $(\sim 150 \mathrm{~nm}) /$ Spiro-OMeTAD/Ag. We obtained functioning devices in both configurations with stabilized power outputs (SPOs) of over $4 \%$, with an average power conversion efficiency (PCE) of $2.5-3 \%$ (see Table S1). Importantly, these working planar devices show that $\mathrm{CsPbI}_{2} \mathrm{Br}$ is capable of generating and transporting charges over hundreds of nanometres without the requirement for distributed heterojunctions, consistent with our previous findings for $\mathrm{CsPbI}_{3}{ }^{[23]}$

Focusing on the planar $\mathrm{c}-\mathrm{TiO}_{2}$ structure, by optimizing the deposition process we fabricated several devices with over $6 \%$ PCE, including a champion device with $9.8 \%$ current densityvoltage $(J-V)$ scan efficiency which delivered 5.6\% SPO. In Figure 3a and b we show histograms of the $J-V$ scan PCEs for a batch of 32 solar cells and SPOs for the best 16 solar cells (see Figure S6 for additional statistics). We note that there is significant variation within a batch, with an average PCE of $6 \%$ and two exceptional devices yielding PCEs above 9\%. We show the $J-V$ scans and SPO measurement for the champion solar cell in Figure 3c and d. We show the key parameters extracted from these scans in Figure 3d (table inset) together with average value statistics for the batch of 32 solar cells. All devices were measured in ambient atmosphere without any encapsulation. To the best of our knowledge, these are the most efficient inorganic perovskite solar cells reported to date. 


\section{WILEY-VCH}
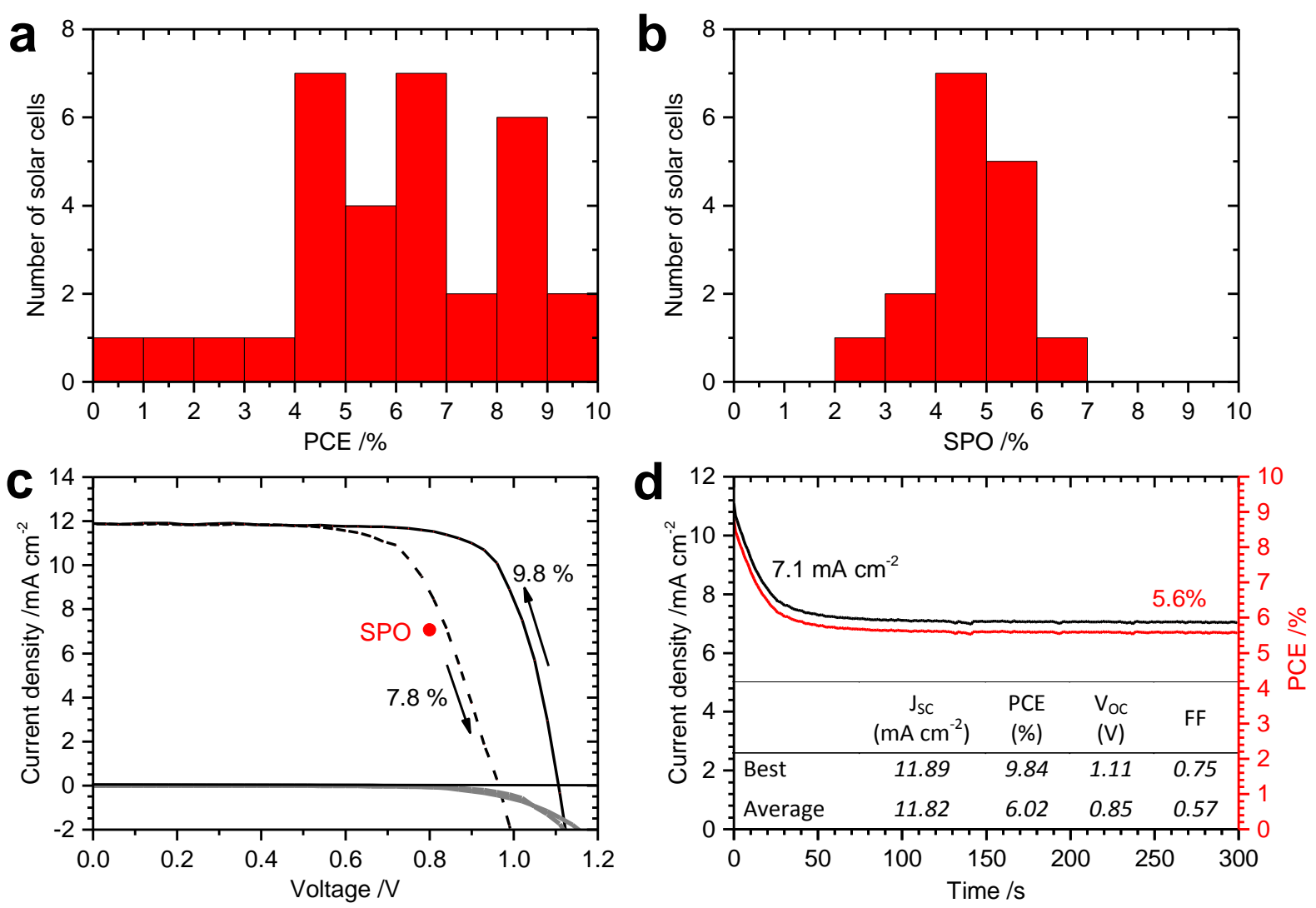

Figure 3. a) Histogram of current density-voltage ( $J-V)$ scan efficiencies for a batch of 32 solar cells. b) Histogram of stabilized power output measurements (SPOs) for the best 16 solar cells in the batch. c) Champion solar cell $J-V$ scans under illumination (black lines) and in the dark (grey lines) from forward bias to short-circuit (solid lines) and from short-circuit to forward bias (dashed lines), and d) Champion solar cell SPO measurement (PCE in red; current density in black). Average values over the last 200 seconds are shown in the figure and the stabilized 'SPO' J-V point is shown in c) by a solid red circle. Solar cell parameters extracted from the $J-V$ scans are shown as a table inset in d) for the champion solar cell in c) and for the batch average of the devices in a) and b).

To put these values into context, the Shockley-Queisser limit for a bandgap of $1.92 \mathrm{eV}$ gives a maximum possible short-circuit current density $\left(J_{S C}\right)$ of $16.3 \mathrm{~mA} \mathrm{~cm}{ }^{-2}$, and a maximum open-circuit voltage $\left(V_{O C}\right)$ of $1.63 \mathrm{~V} \cdot{ }^{[32,33]}$ Hence, although these results are very encouraging, there remains much scope for improvement, particularly in the open-circuit voltage where we still have at least a $0.8 \mathrm{eV}$ voltage deficit (difference between band gap and open-circuit voltage) and are $0.52 \mathrm{~V}$ short of the Shockley-Queisser limit. The voltage deficit has been reduced to less than $0.4 \mathrm{eV}$ in the best reported hybrid perovskite solar cells and thus far we see no fundamental reason why this will not be possible to achieve for these all inorganic 


\section{WILEY-VCH}

perovskite solar cells. We also note that there is also significant hysteresis present in the $J-V$ scan measurements for these devices, similar to our previously reported $\mathrm{CsPbI}_{3}$ solar cells, ${ }^{[23]}$ which may be due in part to the choice of charge extraction layers. For example, swapping $\mathrm{TiO}_{2}$ for $\mathrm{C}_{60}$ as the electron collection layer, ${ }^{[34]}$ or the use of $\mathrm{MoO}_{3}$ as a hole extracting layer have been shown to achieve high PCE and hysteresis suppression with hybrid perovskites and caesium lead iodide devices respectively. ${ }^{[24]}$

In addition, despite increased stability when compared with neat $\mathrm{CsPbI}_{3}$, exposed thin films of $\mathrm{CsPbI}_{2} \mathrm{Br}$ still revert to the yellow phase in air over prolonged exposure to ambient atmosphere (hours or days depending upon the ambient humidity). Hence additional tuning of the crystal may be required to form an appropriately phase stable inorganic perovskite. Further work on optimizing deposition techniques, which has led to steep improvements for the hybrid perovskite solar cells, should lead to significant improvements in these inorganic perovskite devices. There would appear to be no fundamental obstacle stopping the fully inorganic devices matching the hybrid devices in terms of device efficiency, with the added critical advantage that they are significantly more thermally stable, making them much more suitable for long-term commercial deployment, especially for geographic regions of high ambient temperature.

\section{Conclusion}

In summary we have demonstrated that $\mathrm{CsPb}_{2} \mathrm{Br}$ can be used to make solar cells with $5.6 \%$ stabilized power output and with $J$ - $V$ scan efficiencies up to $9.8 \%$. This represents the highest efficiency achieved yet for the fully inorganic lead halide perovskites. By using a mixed halide composition we have significantly improved the ambient stability, as compared to the neat triiodide perovskite previously reported, while still retaining a usefully low bandgap for tandem solar cell applications. These fully inorganic materials show high thermal stability 


\section{WILEY-VCH}

making them a superior candidate for long-term operation under thermally stressful conditions, in comparison to their hybrid counterparts. However, full understanding of the structural stability at ambient temperatures is required to assess the full applicability of these inorganic perovskites to solar power generation. Importantly, this work reinforces the concept that there is nothing intrinsically 'special' about the organic part of organic-inorganic metal halide perovskites, and leads to the possibility of stable inorganic halide perovskites as the next generation of photovoltaic materials.

\section{Supporting Information}

Supporting Information is available from the Wiley Online Library or from the author.

\section{Acknowledgements}

The research leading to these results has received funding from the EPSRC and from the Seventh Framework Programme FP7/2007-2013 under MESO grant agreement ${ }^{\circ}$ [604032]. The authors would like to thank Dr. Bernard Wenger and Prof. Laura Herz for enabling the phase stability and PL measurements respectively. R.S. is a Commonwealth Scholar, funded by the UK government. GE was supported by EPSRC and Oxford PV Ltd. through a Nanotechnology KTN CASE award.

Received: ((will be filled in by the editorial staff))

Revised: ((will be filled in by the editorial staff)) Published online: ((will be filled in by the editorial staff))

\section{References}

[1] A. Kojima, K. Teshima, Y. Shirai, T. Miyasaka, J. Am. Chem. Soc. 2009, 131, 6050.

[2] H. Zhou, Q. Chen, G. Li, S. Luo, T. -b. Song, H.-S. Duan, Z. Hong, J. You, Y. Liu, Y. Yang, Science 2014, 345, 542.

[3] N. J. Jeon, J. H. Noh, W. S. Yang, Y. C. Kim, S. Ryu, J. Seo, S. Il Seok, Nature 2015, 517, 476. 


\section{WILEY-VCH}

[4] C. Roldán-Carmona, P. Gratia, I. Zimmermann, G. Grancini, P. Gao, M. Graetzel, M. K. Nazeeruddin, Energy Environ. Sci. 2015, 8, 3550.

[5] G. E. Eperon, S. D. Stranks, C. Menelaou, M. B. Johnston, L. M. Herz, H. J. Snaith, Energy Environ. Sci. 2014, 7, 982.

[6] B. Conings, J. Drijkoningen, N. Gauquelin, A. Babayigit, J. D’Haen, L. D’Olieslaeger, A. Ethirajan, J. Verbeeck, J. Manca, E. Mosconi, F. De Angelis, H.-G. Boyen, Adv. Energy Mater. 2015, 5, DOI 10.1002/aenm.201500477.

[7] T. Leijtens, G. E. Eperon, N. K. Noel, S. N. Habisreutinger, A. Petrozza, H. J. Snaith, Adv. Energy Mater. 2015, 5, DOI 10.1002/aenm.201500963.

[8] a) See IEC 61646/IEC 61215 (Section 10.11); b) C. R. Osterwald, T. J. McMahon, Prog. Photovoltaics Res. Appl. 2009, 17, 11.

[9] T. Baikie, Y. Fang, J. M. Kadro, M. Schreyer, F. Wei, S. G. Mhaisalkar, M. Graetzel, T. J. White, J. Mater. Chem. A 2013, 1, 5628.

[10] Y. Liu, Z. Yang, D. Cui, X. Ren, J. Sun, X. Liu, J. Zhang, Q. Wei, H. Fan, F. Yu, X. Zhang, C. Zhao, S. F. Liu, Adv. Mater. 2015, 27, 5176.

[11] J.-W. Lee, D.-H. Kim, H.-S. Kim, S.-W. Seo, S. M. Cho, N.-G. Park, Adv. Energy Mater. 2015, 5, DOI 10.1002/aenm.201501310.

[12] D. P. McMeekin, G. Sadoughi, W. Rehman, G. E. Eperon, M. Saliba, M. T. Hörantner, A. A. Haghighirad, N. Sakai, L. Korte, B. Rech, M. B. Johnston, L. M. Herz, H. J. Snaith, Science In press, DOI 10.1126/science.aad5845.

[13] H. L. Wells, Zeitschrift fur Anorg. Chemie 1893, 3, 195; Am. J. Sci. 1893, 45, 121.

[14] C. K. Moller, Nature 1958, 182, 1436.

[15] D. Fröhlich, K. Heidrich, H. Künzel, G. Trendel, J. Treusch, J. Lumin. 1979, 18-19, 385.

[16] S. Sharma, N. Weiden, A. Weiss, Zeitschrift für Phys. Chemie 1992, 175, 63.

[17] S. Kondo, T. Sakai, H. Tanaka, T. Saito, Phys. Rev. B 1998, 58, 11401.

[18] M. Rodová, J. Brožek, K. Knížek, K. Nitsch, J. Therm. Anal. Calorim. 2003, 71, 667.

[19] D. M. Trots, S. V. Myagkota, J. Phys. Chem. Solids 2008, 69, 2520.

[20] G. Murtaza, I. Ahmad, Phys. B Condens. Matter 2011, 406, 3222.

[21] C. C. Stoumpos, C. D. Malliakas, J. A. Peters, Z. Liu, M. Sebastian, J. Im, T. C. Chasapis, A. C. Wibowo, D. Y. Chung, A. J. Freeman, B. W. Wessels, M. G. Kanatzidis, Cryst. Growth Des. 2013, 13, 2722.

[22] M. Kulbak, D. Cahen, G. Hodes, J. Phys. Chem. Lett. 2015, 6, 2452. 


\section{WILEY-VCH}

[23] G. E. Eperon, G. M. Paternò, R. J. Sutton, A. Zampetti, A. A. Haghighirad, F. Cacialli, H. J. Snaith, J. Mater. Chem. A 2015, 3, 19688.

[24] T. S. Ripolles, K. Nishinaka, Y. Ogomi, Y. Miyata, S. Hayase, Sol. Energy Mater. Sol. Cells 2016, 144, 532.

[25] L. Protesescu, S. Yakunin, M. I. Bodnarchuk, F. Krieg, R. Caputo, C. H. Hendon, R. X. Yang, A. Walsh, M. V. Kovalenko, Nano Lett. 2015, 15, 3692.

[26] D. Zhang, S. W. Eaton, Y. Yu, L. Dou, P. Yang, J. Am. Chem. Soc. 2015, 137, 9230.

[27] J. Song, J. Li, X. Li, L. Xu, Y. Dong, H. Zeng, Adv. Mater. 2015, 27, 7162.

[28] D. T. Moore, H. Sai, K. Wee Tan, L. A. Estroff, U. Wiesner, APL Mater. 2014, 2, 081802.

[29] G. Nedelcu, L. Protesescu, S. Yakunin, M. I. Bodnarchuk, M. J. Grotevent, M. V. Kovalenko, Nano Lett. 2015, 15, 5635.

[30] D. M. Jang, K. Park, D. H. Kim, J. Park, F. Shojaei, H. S. Kang, J.-P. Ahn, J. W. Lee, J. K. Song, Nano Lett. 2015, 15, 5191.

[31] S. P. Bremner, M. Y. Levy, C. B. Honsberg, Prog. Photovoltaics Res. Appl. 2008, 16, 225.

[32] W. Shockley, H. J. Queisser, J. Appl. Phys. 1961, 32, 510.

[33] W. Tress, N. Marinova, O. Inganäs, M. K. Nazeeruddin, S. M. Zakeeruddin, M. Graetzel, Adv. Energy Mater. 2015, 5, DOI 10.1002/aenm.201400812.

[34] K. Wojciechowski, T. Leijtens, S. Siprova, C. Schlueter, M. T. Hörantner, J. T.-W. Wang, C.-Z. Li, A. K.-Y. Jen, T.-L. Lee, H. J. Snaith, J. Phys. Chem. Lett. 2015, 6, 2399. 


\section{WILEY-VCH}

Bandgap-Tunable Caesium Lead Halide Perovskites with High Thermal Stability for Efficient Solar Cells

R. J. Sutton, G. E. Eperon, L. Miranda, E. S. Parrott, B. A. Kamino, J. B. Patel, M. T. Hörantner, M. B. Johnston, A. A. Haghighirad, D. T. Moore, and H. J. Snaith*

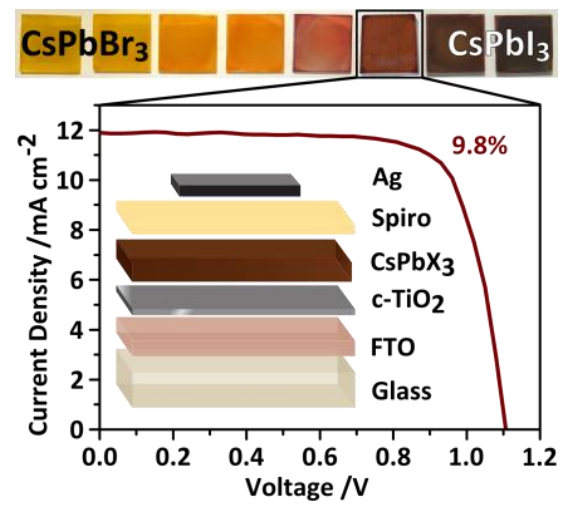

Highest reported efficiency caesium lead halide perovskite solar cells were realized by tuning the bandgap and stabilizing the black perovskite phase at lower temperatures. $\mathrm{CsPbI}_{2} \mathrm{Br}$ was employed in a planar architecture device resulting in $9.8 \%$ power conversion efficiency and over 5\% stabilized power output. Offering substantially enhanced thermal stability over their organic based counterparts, these results show that all-inorganic perovskites could represent a promising next step for photovoltaic materials.

Keywords: perovskite, solar cells, inorganic perovskites, photovoltaics, thermal stability, caesium 